\title{
Empirical Evaluation of Human Factors that Affect Design of the Product
}

\author{
Rashmi Bakshi \\ Department of Information Technology \\ Vivekananda Institute of Professional Studies \\ New Delhi India
}

\author{
Sachin Gupta \\ Department of Information Technology \\ Vivekananda Institute of Professional Studies \\ New Delhi India
}

\begin{abstract}
Workplace safety, human errors, human capability in terms of executing work and contribution in decision making are examples of human factors that affect the design of any product. Human Factors that affect the design of an interface have been explored in this present research.
\end{abstract}

Purpose of this research is to conduct an exploratory study to gather User's perception and Designer's viewpoint in relation with different human factors that influence the design of a product. An empirical evaluation is performed for the identified human factors.

Methodology separate questionnaires and interviews were conducted to gather user's perception and designer's ideology. The responses were considered as primary data which were further used to identify factors that affect the performance of the designer. Similarly, factors affecting the proficiency of the user were identified and tested statistically to check whether the proposed factors identified during the research are significant or not.

Originality Psychology of designers is taken into account in order to increase the efficiency of the product and reduce associated risks like injury during the product development. This research also discusses psychological aspects of users in order to maximise the usability of the product. An exploratory research is conducted to gather their views.

\section{Keywords}

Human factors, Psychology, Ergonomics, Usability testing, Product design, Error Prevention

\section{INTRODUCTION}

Human factor is a scientific study of the mental interaction between people, machines and their work environment with an emphasis on organisational and psychological interaction. [8] It is an overall efficiency that includes cognition. Ergonomics can be seen as a sub set of human factors that deals with physical efficiency of the machine. It uses scientific methods to improve system performance and prevent any accidental harm. An interface can be defined as the sum of the hardware and software components through which a system is operated and users are informed about it. Hardware components include input and output devices (mouse, keyboard, monitor and speaker).Software components include menu commands, icons, windows, pop up messages, navigation styles, information feedback. Software and hardware components of an interface may be linked so tightly that they seem to be inseparable (function keys on keyboards). The interface includes everything the user perceives, understands and manipulates while interacting with the computer. [14] It is therefore an important determinant of human -machine relation. [18]

There are certain myths existing about human factors. [19]Study of human factors is not about elimination of errors rather designing systems that can withstand unanticipated events. Human factors addresses the design problems by studying user's pattern thereby modifying the design so as to adapt to the user's behaviour. It doesn't train or educate users to change their behaviour. Human factors deal with the improvement of technological design, organisational structure and procedure of development in order to satisfy the users. In simple words, No user is stupid. It is the faulty design. Human factors are not only focused on individuals. Rather its work ranges from individual to organisational level.

\section{NEED FOR UNDERSTANDING HUMAN FACTORS}

Before moving towards factors that influence the design of an interface, we must understand the need for studying these factors. Designers need to understand that current users of their product/ software are not scientists or engineers rather they are common people with limited or no technical skills. Therefore demand for user friendly systems increased in the market. Interfaces must be efficient in order to adapt and fulfil growing needs of variety of users. Users vary in age, culture, gender, language and personal interests. Efficient design is the one that is flexible and cater towards range of expectations thereby increasing the demand for the product. Quality of interfaces need to be evaluated depending upon economic status of variety of users. Intense market competition and increased safety expectations are another reason to develop user friendly interfaces by understanding human factors. [18]

\section{ADVANTAGES OF EFFICIENT INTERFACES}

Increased productivity, reduced errors, reduced training and support, improved acceptance and enhanced reputation are the advantages of efficient interfaces. [11]Designing efficient interfaces increase sales of the product. It also helps in developing the positive image of the product. It helps in grasping positive feedback from the users and thus increases the popularity of the software. For business, good interfaces leads to higher staff productivity, lower staff turnover, higher staff morale and higher job satisfaction. Effective interfaces will require less maintenance and after sales services by improving the quality of the design. User friendly design leads to shorter training period required by users to operate the product. It is easy to learn and use thereby reducing the cost of training. Design created by considering human factors in mind will have minimum risk of errors and accidents that can happen during the process of development. Good design also results in reduction of guide manuals and documentation for 
users to follow. Efficient design reduces the probability of frequency of errors from the user's end. Reduction of the time needed to execute a task and increase in autonomy while using the system are also advantages of an effective interface design. [18] It also results into increase in user's satisfaction. Users should be allowed to carry out tasks safely, efficiently, effectively and enjoyably. [20]

\section{LITERATURE REVIEW}

Table 4.1, discusses relevant research papers that took an initiative to understand and list key principles in design and ways of improving the usability by conducting an exploratory study and empirical evaluation.

Table 4.1 Literature Review of previous work

\begin{tabular}{|c|c|c|}
\hline Author & Objective & Methodology \\
\hline MacLean et al.(1991)[12] & $\begin{array}{l}\text { Design space analyses are conducted to } \\
\text { resolve certain design issues and bridge } \\
\text { the gap between design theory and } \\
\text { practice. }\end{array}$ & $\begin{array}{l}\text { QOC notation is used. Where q represents } \\
\text { questions that highlight key issues in the design } \\
\text { decisions. } \\
\text { O stands for options which are effective answers } \\
\text { to the questions. } \\
\text { C symbolises criteria which are the reasons that } \\
\text { argue for and against the possible option. }\end{array}$ \\
\hline Nielsen et al. (1992)[16] & $\begin{array}{l}\text { Gave usability engineering model that } \\
\text { is an extended version of Lewis rules. }\end{array}$ & $\begin{array}{l}\text { Life cycle is normally defined as starting when a } \\
\text { software product is conceived and the ending } \\
\text { when the product is longer in use. This study } \\
\text { moves beyond this period because of the impact } \\
\text { of design decisions on future products and their } \\
\text { life cycles. }\end{array}$ \\
\hline Gould, Lewis (1985)[7] & $\begin{array}{l}\text { Listed three key design principles- and } \\
\text { designer's perspective. }\end{array}$ & $\begin{array}{l}\text { System planners, Designers, Programmers and } \\
\text { developers were selected to write down key steps } \\
\text { involved in order to build and evaluate computer } \\
\text { system for end users. }\end{array}$ \\
\hline Shneiderman , Plaisant(2005)[20] & $\begin{array}{l}\text { It elaborates process of developing user } \\
\text { friendly interactive systems. }\end{array}$ & $\begin{array}{l}\text { It lists guidelines such as Universal usability, } \\
\text { Physical abilities, Workplace design, personality, } \\
\text { cultural diversity. It discusses development } \\
\text { process, interaction styles and design issues. }\end{array}$ \\
\hline Lowgren(1995)[10] & $\begin{array}{l}\text { Gap between theoretical design models } \\
\text { and applications in design is reduced } \\
\text { by understanding engineering design } \\
\text { and creative design. }\end{array}$ & $\begin{array}{l}\text { Empirical studies, personal experience and real } \\
\text { time projects are analysed in order to strengthen } \\
\text { the fact that tension exists between design } \\
\text { principles in theory and design in action. }\end{array}$ \\
\hline Edwards(2008)[5] & $\begin{array}{l}\text { It discusses importance of utilising } \\
\text { human factors in bio medical } \\
\text { inventions. }\end{array}$ & $\begin{array}{l}\text { It mentions hazards occurring in medical devices } \\
\text { that can lead to serious injury and fall out of the } \\
\text { product, safety measures. It discusses usability as } \\
\text { well as marketing perspective. }\end{array}$ \\
\hline Robert et al. (2011)[18] & $\begin{array}{l}\text { Tasks, users, needs and context } \\
\text { analysis are necessary for building } \\
\text { efficient interfaces. }\end{array}$ & $\begin{array}{l}\text { Exploratory study, prototyping and user } \\
\text { evaluation in terms of feedback are conducted } \\
\text { for usability testing }\end{array}$ \\
\hline Chilana et al. (2012)[3] & $\begin{array}{l}\text { An impressive case study of the design } \\
\text { of social networking website popularly } \\
\text { known as Face book is presented from } \\
\text { designers, engineers, managers, users, } \\
\text { experienced researchers, and other } \\
\text { stakeholders at the company. }\end{array}$ & $\begin{array}{l}\text { Face to face interviews were conducted with } \\
\text { engineers, managers and designers working at } \\
\text { face book across different products. Questions } \\
\text { were focussed on design decisions while } \\
\text { focussing new products, sources to gather } \\
\text { information, product stakeholder's perspective. } \\
\text { All the conversation was audio recorded for } \\
\text { analysis. Trade offs in terms of longevity, quality } \\
\text { verses quantity of features are discussed. }\end{array}$ \\
\hline
\end{tabular}




\begin{tabular}{|l|l|l|}
\hline Molich, Jakob Nielsen(1990)[13] & $\begin{array}{l}\text { It focuses on improving an interaction } \\
\text { between human and a computer. }\end{array}$ & $\begin{array}{l}\text { Human Factor Guidelines and Principles are } \\
\text { evaluated by designing an informal dialogue } \\
\text { where participants submitted their entries to } \\
\text { identify the design problems in Manhattan } \\
\text { Telephone system. To stimulate interest in the } \\
\text { contest, price worth \$700 to the best entry. All } \\
\text { entries were evaluated by one person. Selected } \\
\text { 13 entries were judged by three people and the } \\
\text { winner was selected. Grading was liberal. }\end{array}$ \\
\hline Macguire(2001)[11] & $\begin{array}{l}\text { This study lists the benefits of efficient } \\
\text { interfaces, key principles in HCD, } \\
\text { HCD development cycle as given by } \\
\text { ISO. }\end{array}$ & $\begin{array}{l}\text { It involves planning, scoping. Cost-benefit } \\
\text { analysis. Summary of methods for planning, } \\
\text { feasibility. Identify stakeholders, context of use } \\
\text { analysis. }\end{array}$ \\
\hline Souza et al.(1990)[21] & $\begin{array}{l}\text { Existing human factor guidelines were } \\
\text { evaluated on their effectiveness in } \\
\text { redesigning menu interface }\end{array}$ & $\begin{array}{l}\text { A week was given to three designers to study the } \\
\text { guidelines and then redesign the interface by } \\
\text { applying those guidelines in a single day. }\end{array}$ \\
\hline Huang(2009)[9] & $\begin{array}{l}\text { Explores the challenges in interaction } \\
\text { design for mobile devices }\end{array}$ & $\begin{array}{l}\text { Major problem statement in design for mobile } \\
\text { devices is how to provide maximum computing } \\
\text { resources through small interfaces. }\end{array}$ \\
\hline
\end{tabular}

\section{INTER-RELATIONBETWEEN DESIGNER, USER AND CUSTOMER}

User is the one who is actually going to use the product. There can be more than one kind of user using some aspect of the same product for different purposes. An example can be that an I.T organisation purchases query intensive database management system (DBMS) but not all its employees are going to use it for the same purpose. Database Administrator (DBA) will be using it for reading and writing the data whereas database analyst is going to use it to find out how the data is stored. User's needs vary depending upon their nature of work. DBA does not require high level database diagrams and relationships in DBMS software but an analyst needs them to look at it from higher level.

Customer is the one who pays for the product. They evaluate, decide to buy, negotiate and finally pay for it. It can be an individual or a firm buying software for the employees. They can be group of entrepreneurs who might never actually use the system.

Purchasing capability of the Customer directly influences the design of the product. Designers cannot afford to build an expensive design if their intended customers are unwilling to pay high price. It is crucial to study customer's requirements and expectations before beginning the process of designing. Involving customer's opinion in user centred design is often termed as participatory design where customers participate, contribute to build the product and then buy it. In other words, they pay in order to build their niche.

Customer's needs differ from User's needs as they are concerned with purchasing factors like price, company viability, product leadership ,market value etc. They are not concerned with usability or over all user experience with the product.

In this research, in order to avoid complexity, we focussed only on user's needs. User and customer are synonymous which might not be applied in all scenarios.

Also note that, due to evolution in technology, there are scenarios where users do not interact with the computers directly. For example: there are computing devices in the engine of the car but driver interact with the car (interface) and not with these invisible computers. Interfaces need to be carefully designed as interfaces are misinterpreted and assumed as computing devices by users.

\section{USER'S HUMAN FACTORS THAT INFLUENCE THE DESIGN OF AN INTERFACE}

\subsection{Physical dimensions}

Physical abilities of human beings vary according to their physical dimensions. Basic data about human dimensions comes from research in anthropometry. [4; 17] People are grouped according to size, weight, height, gender, age and race. There are hundreds of features including head, mouth, nose, neck, shoulder, chest, arm, leg, finger, foot size to classify people in different groups. The great diversity in these static measures reminds that there can be no image of an "average" user, and that compromises must be made or multiple versions of a system must be constructed. People with especially large or small hands may have difficulty in using standard keyboards, but large number of population is well served by one design. On the other hand, since screenbrightness preferences vary from individual to individual on a large scale, designers customised the feature by enabling user control. Controls for chair seat and back heights and for display angles also allow individual adjustment. When a single design cannot fulfil the needs of a large fraction of the population, multiple versions or adjustment controls are helpful. Physical measures of static human dimensions are not enough. Measures of dynamic actions-such as reach distance while seated, speed of finger presses, or strength of lifting-are also necessary.[1]Since so much of work is related to perception, designers need to be aware of the ranges of human perceptual abilities. [22] Vision is equally important and has been thoroughly studied. [23] Some people are colour blind, either permanently or temporarily (due to illness or medication). Their response time towards visual system will vary from the average user. Designers must consider the needs of people who have eye disorders, damage, or disease, or who wear corrective lenses.

\subsection{General Health and Mental state}

User's general health and mental state affects the state of art in design. User's health affects their decision making capacity. Healthy users are those who have healthy mind along with healthy body. Healthy person is the one whose body is free from any known disease and has positive outlook towards oneself and others in general. Healthy people are usually balanced and sensible in their thoughts, words and actions. 
Unhealthy users not necessarily be suffering from a disease but they have poor life style, habits, negative outlook towards themselves and others. Self-doubt, Instability, Vulnerability and Cynicism are few of the characteristics of an unhealthy person. Their behaviour is not natural and undesirable in the society. Healthy users will not be too critical towards the services offered by the product. Generally healthy users will have no problem in exploring different features of the system without getting tired whereas mentally unstable people will require only relevant features that can fulfil their needs. Healthy users have more tolerance towards the delay of response from the system, slow speed and frequent bugs. Generally healthy users will have good memory and acceptance for the feature requiring considerable amount of their memory usage, even though a design rule suggests that systems should be designed in a way that minimises the memory load of users. In an interface, healthy users will be able to cope up with features demanding better memory as compared to unhealthy users. Mentally ill people lack sense of belonging or self worth therefore system should be able to fill the social emptiness. Great examples of such interfaces are social networking websites (Face book, Twitter) and artificially intelligent Speech recognition application, SIRI. System should be friendly enough so that when the user operates, he feels happy and satisfied. The whole idea of User centred design is to create something that user cannot afford to miss out.

\subsection{Cultural Diversity}

Understanding different cultures is important as it leads towards the increase in sales of the product by improving the acceptance level. Designers find it extremely challenging to establish guidelines designing for multiple languages and cultures.

Shneiderman, Plaisant (2005) lists some of the key features that vary in different cultures. [20]

- Characters, Numerals, Special characters, and Diacriticals

- $\quad$ Left-to-right versus right-to-left versus vertical input and reading

- Date and Time formats

- Numeric and Currency format

- Weights and Measures

- Telephone Numbers and Addresses

- $\quad$ Names and Titles (Mr., Ms., Dr.)

- Social security, National identification, and Passport numbers

- Capitalization and Punctuation

- $\quad$ Sorting sequences

- Icons, Buttons, and Colours

- Pluralisation, Grammar, and Spelling

- Etiquette, Policies, Tone, Formality, and Metaphors

For example, Usually in Indian culture, performance of any product is rated by its cost. General policy is if the product is expensive, it will definitely be good. For Indians, Good design means giant shape, thick, strong and long lasting material, use of vibrant colours, visible and huge logo or brand name to flaunt the device. In Europe, good design means sleek shape, small size, use of neutral colours, simple and elegant with a thin logo as flattery is considered cheap. Understanding these cultural differences will lead to better design and increase in the number of satisfied users.

\subsection{Intelligent Quotient}

Pre- requisites of users must be known in order to avoid thick guide manuals. Design can be complex and high level if user is technical and have been using the system for a long period of time. In this case, user will have no difficulty in adapting and accepting the system. But in case of novice users, Design should be kept simple with few useful and necessary features. 6.5 Workload Measures

Measurement of an effort required by the user while operating the device is also important user's factor in determining the design of the product. Designers should aim at minimum effort yet keep in mind that users do not become too dependent and robotic that they abandon the device in the long run.

\subsection{Personality}

Human beings are comprised of different personality types. Some are excited to use computers where as some are anxious and scared. Some people dislike computers while others are attracted towards them. Often people who dislike computers disapprove their usage and suspect others who are eager to use them. Even people who enjoy using computers may have very different preferences for interaction styles, pace of interaction, graphics versus tabular presentations, dense versus sparse data presentation, step-by-step work versus all-at-once work, and so on. A clear understanding of personality and cognitive styles can be helpful in designing interfaces for a specific community of users. An introvert personality will not be able to communicate well in participatory design and contribute in design decisions. Designers need to understand that users may not know what he wants. If he knows, he may have difficulty in reaching out or confiding his requirements in a structured format. Designers need to remember that user is not a creative designer. Sometimes users have much higher expectations and fantasies about the product that are beyond the scope of implementation. Their suggestions cannot be feasible. Specifying what user wants to do with the system must synchronise with how designer builds the system to do it. Males and females users have different preferences for the system. Their choice of colours in an interface design is different. Their choice of features in software is different. Violent and loud video games having strong graphics are played by large fraction of male users as compared to female users.

\subsection{Special needs}

There are customised solutions for vision impaired, hearingimpaired, and mobility-impaired users, such as keyboard or mouse alternatives, colour coding, font-size settings, contrast settings, textual alternatives to images, and web features such as frames, links, and plug-ins. Screen magnification to enlarge portions of a display or text conversion to Braille or voice output can be done with hardware and software supplied by many vendors.[2]Text-to-speech conversion can help blind users to receive electronic mail or to read text files, and speech-recognition devices permit voice-controlled operation of some software. Learning-disabled children, including dyslexics benefit from the design of special courseware that limits on heavy textual data, difficult presentation formats etc.[15] The benefits to senior citizens include improved chances for productive employment and opportunities to use writing, accounting, and other computer tools, plus the satisfactions of education, entertainment, social interaction, and challenge.[6] 


\section{DESIGNER'S HUMAN FACTORS THAT AFFECT THE DESIGN OF AN INTERFACE}

Designers need to focus at functions offered by the product. There is a need to conduct brainstorming sessions in order to explore tasks and sub-tasks needed to carry out in the development cycle. This process is known as task analysis. There is a need to gain trust of users in the system. Designers and developers also need to meet the timelines and deliver the product in time so as to avoid additional costs. They have to work with limited resources and deal with ongoing pressures rising from the client side, boss and other team mates. They need to build friendly relations with their co workers so as to reap maximum benefit out of them. They have to be spontaneous and acquire an ability to think fast and accurate in times of crises or emerge of an unknown situation. They need to develop strategies and tactics to solve a complicated problem. They should be willing to compromise their self interest to withstand the general interest of the company or the product. They are required to work tirelessly so as to produce good quality product with existing limitations. They need to test the product prototype multiple times with different kind of users, also known as usability testing at an early stage so as to ensure that the product is user-friendly and bug - free to its maximum level. This will further save the team from additional costs of rectifying errors at the later stage of design. They need to ensure that interaction between the system and user is effective, efficient and satisfactory. Effectiveness: the degree of success with which users achieve their task goals. Efficiency: the time it takes to complete tasks. Satisfaction: User comfort and acceptability. [11]

\subsection{Reliability}

It refers to the level of confidence user gains while using the system. User must be able to trust that system will deliver expected outcomes.

\subsection{Standardization}

It refers to common features of the interface adapted by different platforms and applications.

\subsection{Consistency}

It refers to common action sequences, terms, units, layouts, colours, typography and so on within an application program. Consistency determines the success of interfaces. It includes compatibility across application programs. [20]

\subsection{Portability}

It refers to the potential to convert data and to share user interfaces across multiple software and hardware environments. Portability is a challenge for designers, who must contend with different display sizes and resolutions, colour capabilities, pointing devices, data formats.[20]

\subsection{Scalability}

It refers to the ability of a system to accommodate new features and new users while retaining the old ones. It means a substantial increase in size so as to support additional requirements.

Designers need to answer the following questions before dipping their hands deep in the designing process.

Does the system understands and supports user's goals?

What are the functions of the system? Do they match with the user's needs?

Is the system reliable? Can it support user's needs in the long term?

What kind of standardization is required by the system to grab long term users?

As users begin to move rapidly from one location to another for work or pleasure, can the system support it? Is the system portable?

As the system becomes popular, number of users will increase. Is the system scalable?

As users evolve, their needs change. Is the system flexible?

Table 7.1: lists the user's and designer's factors that influence the design of the product

\begin{tabular}{|l|l|}
\hline User's factors & Designer's factors \\
\hline Physical ability, & Understanding user's goals* \\
\hline $\begin{array}{l}\text { General Health and Mental State } \\
\text { Edward(2008)[5] }\end{array}$ & Functionality* \\
\hline Cultural Diversity & Reliability* \\
Shneiderman,Plaisant(2005)[20] & \\
\hline Intelligent Quotient* & \\
\hline Special Needs & Standardisation \\
Shneiderman, Plaisant (2005)[20] & Integrity* \\
\hline Personality & \\
Shneiderman, Plaisant (2005)[20] & Consistency \\
\hline $\begin{array}{l}\text { Subjective Satisfaction } \\
\text { Nielsen(1992)[16] }\end{array}$ & Shneiderman, Plaisant (2005)[20] \\
\hline
\end{tabular}




\begin{tabular}{|c|c|}
\hline & Shneiderman, Plaisant (2005)[20] \\
\hline Effort Required* & Quality* \\
\hline \multicolumn{2}{|l|}{ Nielsen(1992)[16] } \\
\hline & $\begin{array}{l}\text { Schedules and budgets } \\
\text { Nielsen(1992)[16] }\end{array}$ \\
\hline & $\begin{array}{l}\text { Workplace environment(friendly atmosphere, strong team, good boss, increase in } \\
\text { salary)* }\end{array}$ \\
\hline & $\begin{array}{l}\text { Rewards( Tangible- Salary Increment/bonus, higher authority; Intangible-Respect, } \\
\text { Recognition, Motivation, High Confidence)* }\end{array}$ \\
\hline & Innovation (Creative-design is an art ,Intuitive)* \\
\hline & Technical proficiency $*$ \\
\hline & Decision making capability* \\
\hline & Amount of workload- workload detection and measurement $*$ \\
\hline
\end{tabular}

* are human factors proposed in this current research.

\section{RESEARCH METHODOLOGY}

The empirical study has been conducted by means of questionnaire to seek the existence of various human factors proposed in the table 7.1. Questionnaire is formed based on Likert's scale and open text questions. About 80 responses from designers and developers working in different organisations are taken under study using convenient sampling. The aim of this research is to explore the existence of proposed designer's factors. 120 user's feedbacks are studied to test the performance of proposed user's factors.

The following null hypotheses have been formed based on the data collected.

8.1 $\mathrm{H}_{0}$ : Knowledge of user's goals and requirements does not affect on designer's performance.

8.2 $\mathrm{H}_{0}$ : There is no contribution of features with in a system on designer's performance.

$8.3 \mathrm{H}_{0}$ : There is no significant impact of designer's workplace environment and rewards on design of the product.

8.4 $\mathrm{H}_{0}$ : Creative but technically weak designer gives poor performance in product design.

8.5 $\mathrm{H}_{0}$ : There is no significant impact of designer's decision making ability on his performance.

8.6 $\mathrm{H}_{0}$ : Effort required by the user to operate the product does not have any influence on user's performance.

8.7 $\mathrm{H}_{0}$ : There is no significant impact of User's technical proficiency on his performance.

\section{STATISTICAL ANALYSES}

$9.172 \%$ designers are aware of their intended customers. They understand the need to communicate with their customers throughout the product development cycle in order to understand their requirements.

The computed value of $\mathrm{z}$ statistics is 3.92 ; therefore at $5 \%$ level of significance the proposed null hypothesis has been rejected proving that information about user's goals and requirements has an influence upon designer's performance.
$9.243 \%$ designers understand the importance of usability testing, willing to change the design (addition and removal of features) on their user's consent. The computed value of $\mathrm{z}$ statistics is 1.36 thus it accepts the null hypothesis at 5\% significance level stating that there is no relation between designer's performance and features of the system.

9.3 $91 \%$ designers agree that low salary, strict boss, limited budget and pressure of meeting deadlines affect their productivity which in turn results in poor design.

The computed value of $\mathrm{z}$ statistics is 7.32 which reject the null hypothesis and proves that workplace environment impacts the designer's performance.

$9.446 \%$ designers agree that technical modalities can be taught and learnt in a period of time but "out of box" thinking helps to become successful.

The computed value of $\mathrm{z}$ statistics is 0.716 accepts the null hypothesis which proves that technically weak designers perform poorly.

9.5 58\% designers feel that freedom at work, transparency ad removal of hierarchy can improve their performance while $40 \%$ agreed upon limited freedom so as to avoid confusion, manipulation and counter productivity.

The computed value of $\mathrm{z}$ statistics is 1.42 thus null hypotheses is accepted stating that there is no influence of designer's decision making ability on his performance.

9.6 37\% users are not tech enthusiasts and do not regularly operate technical devices. They agree that effort required should be minimum as they find devices difficult and complicated. The computed value of $\mathrm{z}$ statistics is 2.83 thus null hypothesis has been rejected confirming that effort required by the user influences his performance. 
9.7 $39 \%$ users do not have prerequisites to operate the devices. Lack of usage and technical skills results in having perceived complexity towards technology. The computed value of $\mathrm{z}$ statistics is 2.40 which means that null hypothesis is rejected hence it is proved that user's technical skills have an impact on their performance.

\section{CONCLUSION}

An exploratory study was conducted to identify human factors that affect designer's and user's performance in terms of system design. The proposed factors where further statistically tested to find out their significance. Psychological perspective was kept in mind during the exploratory study. Designers were interviewed in an informal way during the weekends so as to make sure their responses were not biased. Structure of questionnaire was kept easy and simple so as to avoid exhaustion and irritation from the other end. It was a voluntary participation of Designers and Users rather than an imposed one. All participants were made comfortable and given an introduction about the intend of research so as to avoid any kind of anxiety among them which might influence their response. However it was a conditioned research with its constraints and limitations.

\section{REFERENCES}

[1] Bailey, Robert W. Human Performance Engineering: Using Human Factors/Ergonomics to Achieve Computer Usability, Prentice-Hall, Third Edition, Englewood Cliffs, NJ (1996).

[2] Blenkhorn, Paul, Evans, Gareth, King, Alasdair, Kurniawan, Hastuti, Sutcliffe, Alistair. Screen magnifiers: Evolution and evaluation. IEEE Computer Graphics and Applications, 23, 5 (Sept/Oct 2003), 54-61.

[3] Chilana, P.K., Holsberry, C., Oliveira, F., Ko, A.J. Designing for a Billion Users: A Case Study of Facebook. CHI, 2012

[4] Dreyfus, W. The Measure of Man: Human Factors in Design. Whitney Library of Design, Second Edition, 1967.

[5] Edwards,Evan T., The Importance of Utilizing Human Factors Engineering in Developing Biomedical Innovation, Intelliject, LLC, 2008.

[6] Furlong, Mary, Kearsley, Greg. Computers for Kids Over 60, SeniorNet, San Francisco, CA(1990).

[7] Gould, J.D., Lewis, C. Designing for Usability: Key Principles and What Designers Think. Human Aspects of Computing Communications of the ACM, 1985, volume 28

[8] Helander,M.Handbook of Human Computer Interaction, 1990
[9] Huang,K.Y.Challenges in Human-Computer Interaction Design for Mobile Devices. Proceedings of the World Congress on Engineering and Computer Science, 2009, Vol I

[10] Lowgren, J. Applying Design Methodology to Software Development. DIS, ACM, 1995

[11] Macguire, M. Methods to support human-centred design. Int. J. Human-Computer Studies, 2001

[12] MacLean, A., Young, R. , Bellotti ,V., Moran, T. Design Space Analysis: Bridging from Theory to Practice via Design Rationale. Proceedings of Esprit '91, Belgium, pp 720-730.

[13] Molich, R., Nielsen, J. Improving a Human- Computer Dialogue .Communications of the ACM , March 1990, Volume 33 .

[14] Moran, TP., The command language grammar: A representation for the user interface of interaction computer systems. Int. J Man Mach Stud, 15:3-50, 1981.

[15] Neuman, Delia. Learning disabled students' interactions with commercial courseware: A naturalistic study. Educational Technology Research Development, (1991), 31-49.

[16] Nielsen, J., Bellcore. The usability engineering life cycle. IEEE, Computer (Mar.):12-22.

[17] Pheasant, Stephen. Body space: Anthropometry, Ergonomics and the Design of the Work.CRC Press, Second Edition, 1996.

[18] Robert, Marc J., Ergonomic Aspects of HumanComputer Interaction, Encyclopaedia of Occupational Health and Safety, International Labour Organization, Geneva. 2011.

[19] Russ, L.A. The science of human factors: separating fact from fiction, $B M J, 2013$.

[20] Shneiderman, B., Plaisant, C. Designing the user interface. Strategies for effective human computer interaction, university of Maryland, 4th Edition, 2005.

[21] Souza, F.D., Bevan, N. The use of guidelines in menu interface design, Proceedings of IFIP interact'90.Human-Computer Interaction, 1990, p.435440.

[22] Ware, Colin. Information Visualization: Perception for Design. Morgan Kaufmann Publishers, Second Edition, San Francisco, CA (2004).

[23] Wickens, Christopher D., Hollands, Justin G. Engineering Psychology and Human Performance. Prentice-Hall, Englewood Cliffs, NJ (2000). 